\begin{tabular}{|c|c|}
\hline Title & Generation of alkali-free and high-proton concentration layer in a soda lime glass using non-contact corona discharge \\
\hline Author(s) & Ikeda, Hiroshi; Sakai, Daisuke; Funatsu, Shiro; Y amamoto, Kiyoshi; Suzuki, Toshio; Harada, Kenji; Nishii, Junji \\
\hline Citation & $\begin{array}{l}\text { Journal of A pplied Physics, 114(6), 063303-1-063303-6 } \\
\text { https://doi.org/10.1063/1.4817760 }\end{array}$ \\
\hline Issue Date & $2013-0814$ \\
\hline Doc URL & http:/hdl.handle.net/2115/53295 \\
\hline Rights & $\begin{array}{l}\text { Copyright } 2013 \text { A merican Institute of Physics. This article may be downloaded for personal use only. A ny other use } \\
\text { requires prior permission of the author and the A merican Institute of Physics. The following article appeared in J. A ppl. } \\
\text { Phys. 114, } 063303 \text { (2013) and may be found at http://Jap.aip.org/resource/1/ apiau/114/6/p063303_s1 }\end{array}$ \\
\hline Type & article \\
\hline File Information & JA pplPhys_114_063303.pdf \\
\hline
\end{tabular}

Instructions for use 


\section{AIP Appilied Physics}

Generation of alkali-free and high-proton concentration layer in a soda lime glass using non-contact corona discharge

Hiroshi Ikeda, Daisuke Sakai, Shiro Funatsu, Kiyoshi Yamamoto, Toshio Suzuki et al.

Citation: J. Appl. Phys. 114, 063303 (2013); doi: 10.1063/1.4817760

View online: http://dx.doi.org/10.1063/1.4817760

View Table of Contents: http://jap.aip.org/resource/1/JAPIAU/v114/i6

Published by the AIP Publishing LLC.

\section{Additional information on J. Appl. Phys.}

Journal Homepage: http://jap.aip.org/

Journal Information: http://jap.aip.org/about/about_the_journal

Top downloads: http://jap.aip.org/features/most_downloaded

Information for Authors: http://jap.aip.org/authors

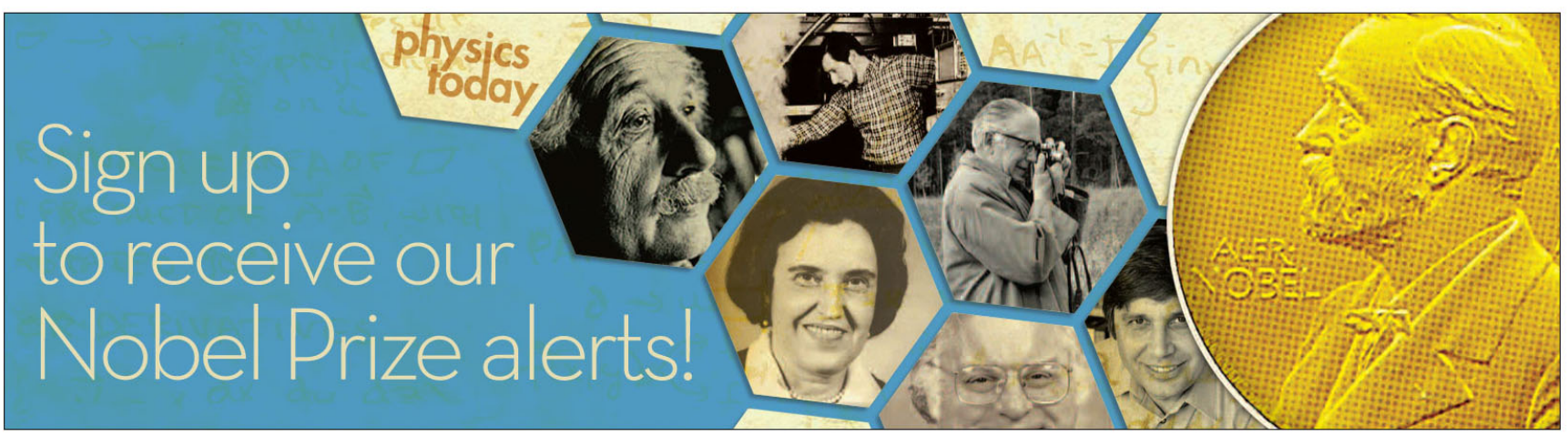




\title{
Generation of alkali-free and high-proton concentration layer in a soda lime glass using non-contact corona discharge
}

\author{
Hiroshi Ikeda, ${ }^{1, a)}$ Daisuke Sakai, ${ }^{1}$ Shiro Funatsu, ${ }^{2}$ Kiyoshi Yamamoto, ${ }^{3}$ Toshio Suzuki, ${ }^{3}$ \\ Kenji Harada, ${ }^{4}$ and Junji Nishii ${ }^{1}$ \\ ${ }^{1}$ Research Institute for Electronic Science, Hokkaido University, N20 W10, Kita-ku, Sapporo, \\ Hokkaido 001-0020, Japan \\ ${ }^{2}$ Production Technology Center, Asahi Glass Co., Ltd., 1-1 Suehiro-cyo, Tsurumiku, Yokohama, \\ Kanagawa 230-0045, Japan \\ ${ }^{3}$ Research Center, Asahi Glass Co., Ltd., 1150 Hazawa-cho, Kanagawa-ku, Yokohama, \\ Kanagawa 221-8755, Japan \\ ${ }^{4}$ Department of Computer Science, Kitami Institute of Technology, 165 Koen-cho, Kitami, \\ Hokkaido 090-8507, Japan
}

(Received 7 June 2013; accepted 23 July 2013; published online 8 August 2013)

\begin{abstract}
Formation mechanisms of alkali-free and high-proton concentration surfaces were investigated for a soda lime glass using a corona discharge treatment under an atmospheric pressure. Protons produced by high DC voltage around an anode needle electrode were incorporated into a sodium ion site in the anode side glass. The sodium ion was swept away to the cathode side as a charge carrier. Then it was discharged. The precipitated sodium was transformed to a $\mathrm{Na}_{2} \mathrm{CO}_{3}$ powder when the surface contacted with air. The sodium ion in the glass surface layer of the anode side was replaced completely by protons. The concentration of $\mathrm{OH}$ groups in the layer was balanced with the amount of excluded sodium ions. The substitution reaction of sodium ions with protons tends to be saturated according to a square root function of time. The alkali depletion layer formation rate was affected by the large difference in mobility between sodium ions and protons in the glass. @ 2013 AIP Publishing LLC. [http://dx.doi.org/10.1063/1.4817760]
\end{abstract}

\section{INTRODUCTION}

Several modification techniques have been developed for glass surfaces, such as ion implantation method, ${ }^{1}$ ionexchange using a molten salt, ${ }^{2}$ and heat-treatment in an active gas. ${ }^{3}$ An externally applied DC voltage also attracts great interest as a modification method. For example, thermal poling, which applies high voltage across the electrodes to a glass with heat treatment, generates an alkali depletion area, including structural defects in the glass, leading to second harmonic generation, and the electrooptical effect. ${ }^{4-10}$ Recently, electro-field imprint processing, which is an imprint technique assisted by DC voltage applied between the molds, ${ }^{11-14}$ has been studied for the fabrication of plasmonic microstructures on the surface of a metal-glass composite material. Corona discharge has been identified as a useful non-contact surface modification method for several materials. ${ }^{15-21}$ The corona is a nondisruptive electrical discharge created by application of a high DC voltage between an anode and a cathode. For example, a material surface on the plate cathode electrode is charged with ions generated around the anode needle electrode, leading to the generation of a large electric field on the material surface. Considerable effort has been devoted to corona discharge treatment for the surface modification of dielectric polymers. ${ }^{15,16,21}$

\footnotetext{
${ }^{\text {a) }}$ Author to whom correspondence should be addressed. Electronic mail: ikeda@astec.kyushu-u.ac.jp. Present address: Art, Science and Technology Center for Cooperative Research, Kyushu University, 6-1 Kasuga-koen, Kasuga, Fukuoka 816-8580, Japan.
}

We previously recorded a hologram on the soda lime glass surface using the corona discharge treatment. ${ }^{22-26}$ Surface-relief gratings of an azobenzene polymer, which were fabricated on the glass surface using two-beam interference, were transferred onto the glass surface after the corona discharge treatment. The treatment conditions strongly affected the diffraction efficiency of the grating formed on the glass surface. However, the formation mechanism of such holographic grating remains ambiguous. This study was undertaken to elucidate the surface modification phenomena of soda lime glasses caused by the corona discharge treatment.

\section{EXPERIMENTAL}

A schematic set up of the corona discharge treatment is shown in Figure 1. A steel needle coated with Pt was used with a flat carbon plate, respectively, as anode and cathode electrodes. The anode electrode was connected to a DC power supply. The cathode electrode was grounded. The current in the circuit was monitored using a data logger (midi Logger GL220; Graphtec Corp.). Commercially available soda lime glass (AS; Asahi Glass Co. Ltd.) was used for the experiment. The sodium and calcium oxide contents were, respectively, $13 \mathrm{~mol} . \%$ and $9 \mathrm{~mol}$. \%. The glass was polished using a colloidal silica compound to suppress the alkali dissolution from its surface during polishing. The glass plate of $25 \mathrm{~mm} \times 25 \mathrm{~mm} \times 1 \mathrm{~mm}$ was placed on the cathode plate. The distance between the needle and the glass surface was $5 \mathrm{~mm}$. The corona discharge treatment was performed at temperatures between $100^{\circ} \mathrm{C}$ and $400^{\circ} \mathrm{C}$ in an atmosphere 


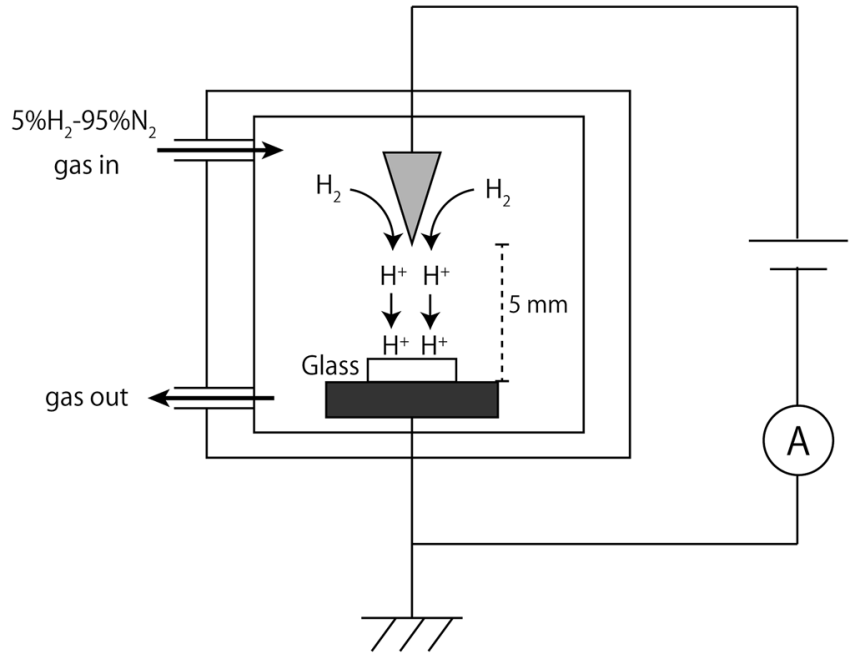

FIG. 1. Corona discharge setup for glass surface treatment. Anode and cathode electrodes are, respectively, a steel needle and a carbon plate. The needle size in the scheme is exaggerated.

of 5 vol. $\% \mathrm{H}_{2}$ and 95 vol. $\% \mathrm{~N}_{2}$. The applied voltage, which was controlled below the arc discharge level, was less than $7 \mathrm{kV}$ for our setup. After treatment, the glass was cooled gradually to room temperature in the furnace.

Infrared (IR) absorption spectra of the treated glass were examined using a Fourier transform infrared absorption spectrometer (FT-IR, Affinity-1; Shimadzu Corp.). White compounds precipitated on the cathode side glass surface were dissolved in distilled water and were analyzed using inductive coupled plasma atomic emission spectroscopy (ICPAES; ICPE-9000; Shimadzu Corp.). The depth profile of the glass composition was analyzed using energy dispersive X-ray spectroscopy (EDS; JED-2300; JEOL Ltd.).

\section{RESULTS}

Voltage-current (V-I) characteristics found during the corona discharge treatment at $100{ }^{\circ} \mathrm{C}$ are shown in Figure 2. At voltages above the threshold of $3.8 \mathrm{kV}$, the corona

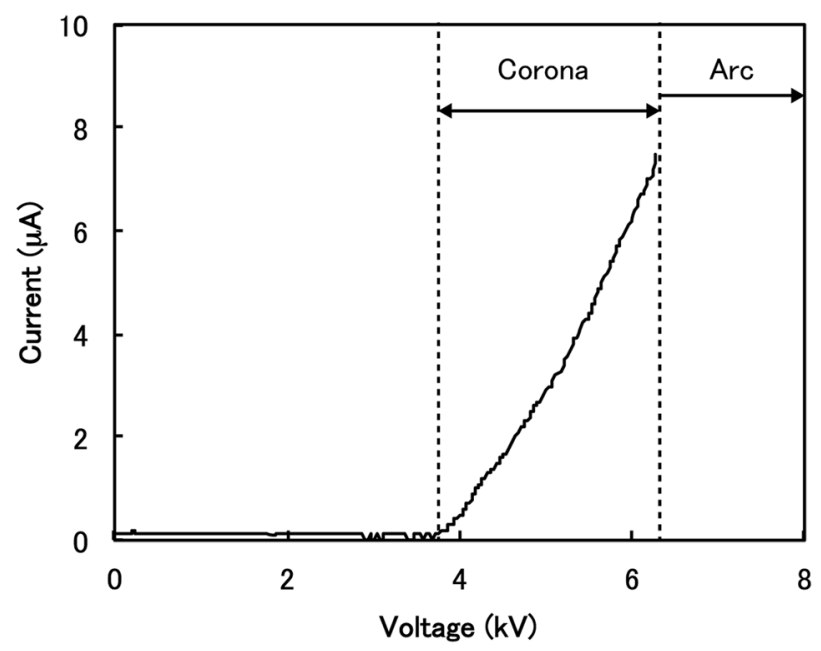

FIG. 2. Relation between applied voltage and current during corona discharge treatment on the soda lime glass surface at $100^{\circ} \mathrm{C}$ in a nitrogen atmosphere containing 5 vol. $\% \mathrm{H}_{2}$.

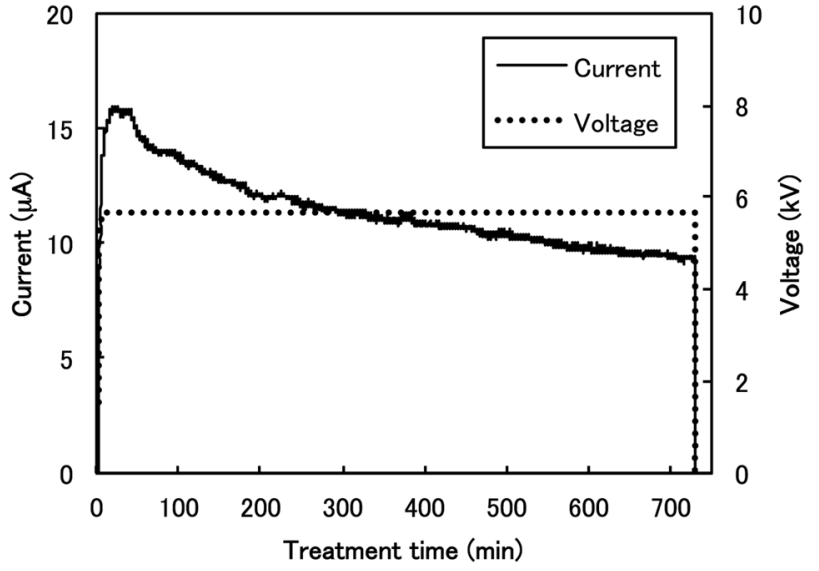

FIG. 3. Time dependence of current during corona discharge treatment on the soda lime glass at $100^{\circ} \mathrm{C}$.

discharge occurred with the ionization of the gas molecules around the anode needle, leading to the current flow, which increased gradually with the applied voltage. When the applied voltage was too high, the corona discharge was transformed to the arc discharge, resulting in fatal surface sputtering damage. Figure 3 presents the time dependence of current during the treatment, which increased to $16 \mu \mathrm{A}$ with the voltage. It subsequently decreased gradually to $9 \mu \mathrm{A}$ after treatment for $720 \mathrm{~min}$. The white precipitates confirmed on the anode side glass surface were identified as $\mathrm{Na}_{2} \mathrm{CO}_{3}$ using ICP-AES and Raman spectroscopy, which should be formed by the chemical reaction of the discharged sodium metal with air including $\mathrm{CO}_{2}$ gas. The amount of the precipitate that had formed after treatment at $100^{\circ} \mathrm{C}$ was higher than those that formed at 200,300 , and $400^{\circ} \mathrm{C}$.

Figure 4 shows the time dependence of the sodium precipitated after the corona discharge treatment at $100^{\circ} \mathrm{C}$ and the applied voltage of $5.7 \mathrm{kV}$. The amount of sodium increased with the treatment time, although no change was found in the precipitated area against the treatment time: it was $16 \mathrm{~mm}$ diameter. Figure 5 shows a cross-section optical view of the glass treated at $100{ }^{\circ} \mathrm{C}$ with $5.7 \mathrm{kV}$ for $720 \mathrm{~min}$. An approximately $3 \mu \mathrm{m}$ thick layer was observed at the

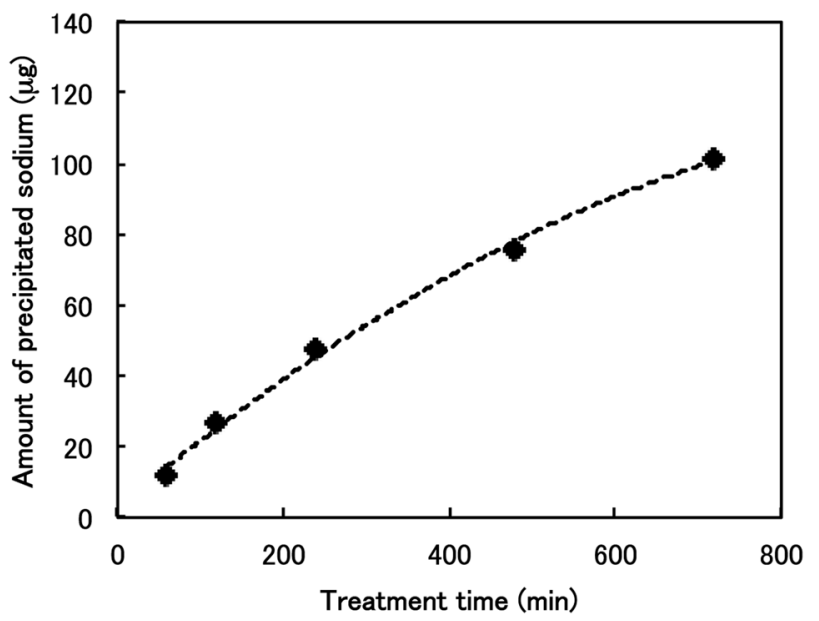

FIG. 4. Relation between corona discharge treatment time and precipitated sodium converted from the amount of $\mathrm{Na}_{2} \mathrm{CO}_{3}$ analyzed using ICP-AES. 


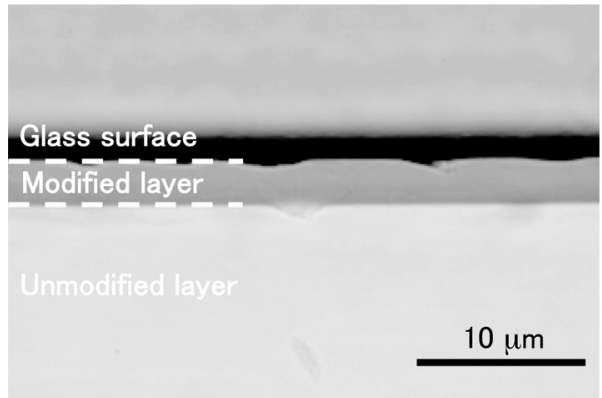

(a) Anode side

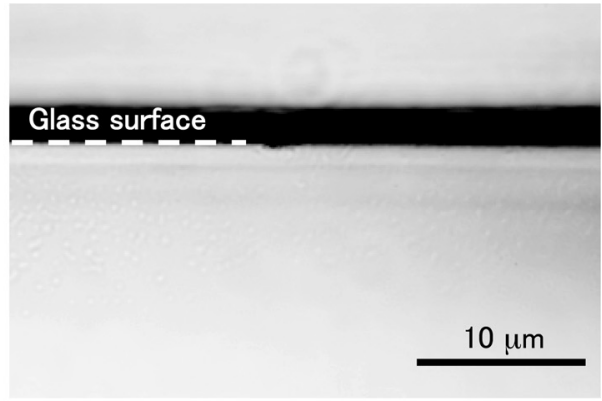

(b) Cathode side
FIG. 5. Cross-sectional glass surface views after corona discharge treatment under applied voltage of $5.7 \mathrm{kV}$ at $100^{\circ} \mathrm{C}$ for $720 \mathrm{~min}$ : (a) anode side and (b) cathode side. anode side glass surface. In contrast, no modified layer was found at the cathode side glass surface. The thin layer composition was analyzed using EDS. Figure 6 presents depth profiles of representative metals in the glass matrix. A steplike sodium depletion layer was confirmed at the anode side surface. The calculated amount of sodium ions in this layer agreed well with the precipitated sodium results obtained using ICP-AES analysis. These results demonstrate that the sodium ions in the glass drifted from the anode side to the cathode side as charge carriers; then they were discharged.

The IR absorption spectra of the glasses were measured before and after the corona discharge treatment. Significant differences were recognized in the wavelength range of $2500-3700 \mathrm{~cm}^{-1}$. Figure 7 portrays spectra after the corona discharge treatment for 60-720 min. Broad peaks were assignable to $\mathrm{OH}$ groups. ${ }^{27}$ These peak intensities increased with the treatment time. The $\mathrm{OH}$ group depth profiles were evaluated through careful polishing of the anode side surface. Figure 8 depicts the IR absorption spectra before and after eliminating the surface layer by approximately $10 \mu \mathrm{m}$. The peak intensities after polishing are apparently reduced to the same level as that of the untreated glass. Therefore, the $\mathrm{OH}$ groups that increased after the corona discharge treatment were located only at the sodium depletion layer.

\section{DISCUSSION}

\section{A. Substitution reaction of sodium ion with proton}

The corona discharge treatment, respectively, induced the sodium depletion layer and the precipitation of $\mathrm{Na}_{2} \mathrm{CO}_{3}$ at the anode and cathode side surfaces. Furthermore, $\mathrm{OH}$ groups were formed in the sodium depletion layer. Therefore, it is evident that the charge carrier during the treatment was sodium ions and that the protons were introduced to the sodium depletion layer as the charge compensator. All of these electrochemical phenomena are explained stoichiometrically as shown in Figure 9, which presents the time dependence of the electrical charges and the amount of precipitated sodium and incorporated $\mathrm{OH}$ groups by the corona discharge treatment at $100^{\circ} \mathrm{C}$. Each value was obtained using the following methods. (a) The electrical charges were estimated by the time integration of the current during corona discharge treatment using the Faraday constant of $96485 \mathrm{C} \mathrm{mol}^{-1}$. Here, the carrier is assumed to be only sodium ion. (b) The amount of the precipitated sodium was analyzed using the ICP-AES (see Figure 4). (c) The OH groups introduced by the corona discharge treatment were estimated from the IR absorption intensities in Figure 7 using the twoband method reported by Scholze. ${ }^{27,28}$ It is possible to calculate the amount of $\mathrm{OH}$ groups from the peaks at $2800 \mathrm{~cm}^{-1}$ and $3500 \mathrm{~cm}^{-1}$ in the IR absorption spectrum of a glass:

$$
O H_{\text {total }}=\frac{V}{d}\left(\frac{\alpha_{3500}}{\varepsilon_{3500}}+\frac{4}{3} \cdot \frac{\alpha_{2800}}{\varepsilon_{2800}}\right) .
$$

In that equation, $d$ stands for the thickness, $V$ is the volume, and $\alpha_{2800}$ and $\alpha_{3500}$, respectively, represent the absorption coefficients at $2800 \mathrm{~cm}^{-1}$ and $3500 \mathrm{~cm}^{-1}$. The absorption coefficients of $1641 \mathrm{~mol}^{-1} \mathrm{~cm}^{-1}$ and $76 \mathrm{lmol}^{-1} \mathrm{~cm}^{-1}$ are used, respectively, for $\alpha_{2800}$ and $\alpha_{3500}$. The thickness $d$ is $1 \mathrm{~mm}$. Volume $V$ is determined from the glass thickness and the corona discharged circle area of $16 \mathrm{~mm}$ diameter. As presented in Figure 9, the total electrical charges, the amounts of precipitated sodium and the total concentration of $\mathrm{OH}$ groups are increased linearly against the square root of the treatment time with a similar slope. Consequently, the

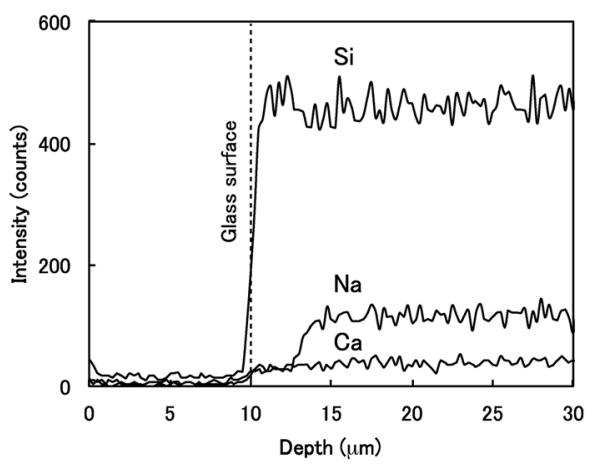

(a) Anode side

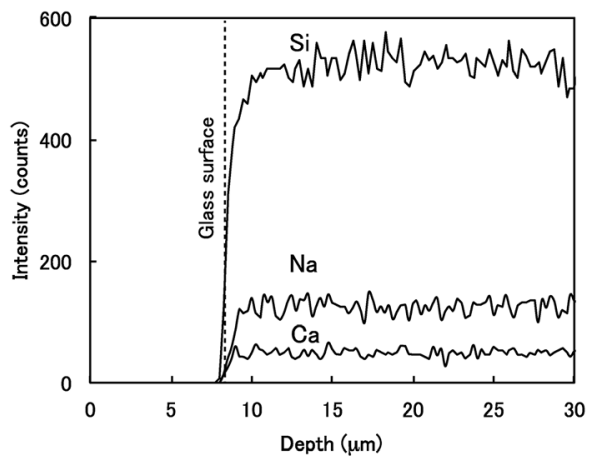

(b) Gathode side 


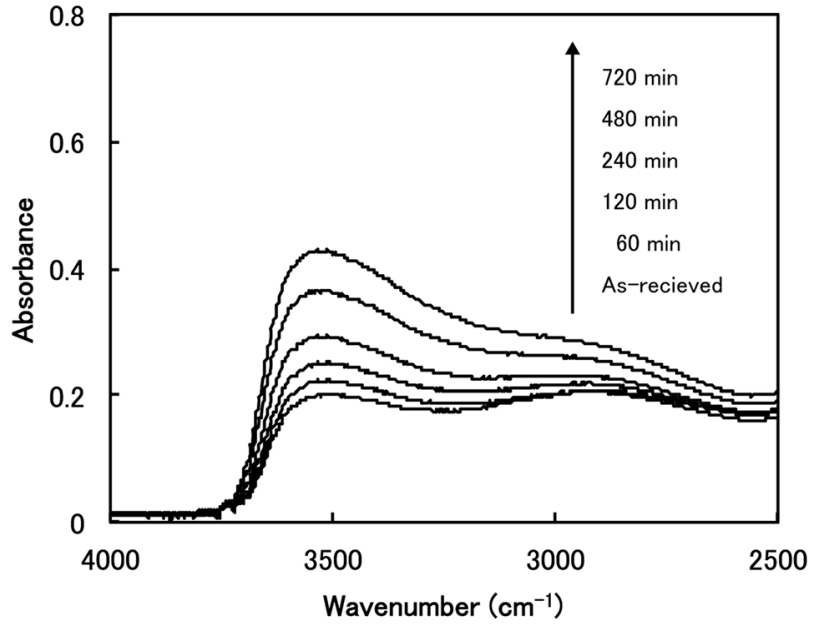

FIG. 7. IR absorption spectra of the soda lime glass after corona discharge treatment at $100^{\circ} \mathrm{C}$.

chemical reactions caused in the soda lime glass by the corona discharge treatment can be expressed as shown below:

$$
\begin{aligned}
& \text { Anode electrode; } \mathrm{H}_{2} \rightarrow 2 \mathrm{H}^{+}, \\
& \text {Anode side glass surface; } \mathrm{Si}-\mathrm{O}^{-} \mathrm{Na}^{+}+\mathrm{H}^{+} \\
& \rightarrow \mathrm{Si}-\mathrm{OH}+\mathrm{Na}^{+},
\end{aligned}
$$$$
\text { Cathode side glass surface; } \mathrm{Na}^{+}+\mathrm{e}^{-} \rightarrow \mathrm{Na} \text {. }
$$

Reactions (2), (3), and (4), respectively, show the ionization of the $\mathrm{H}_{2}$ gas molecule caused by the large electric field at the anode needle electrode, the substitution of sodium ions with protons in the glass network, and the discharge of sodium ions to sodium atoms at the cathode side. The corona discharge in the hydrogen atmosphere generates not only $\mathrm{H}^{+}$, but also $\mathrm{H}_{3}{ }^{+}$and $\mathrm{H}_{5}{ }^{+} \cdot{ }^{29}$ In addition, if a small amount of $\mathrm{H}_{2} \mathrm{O}$ exists in the ambient atmosphere, then $\left(\mathrm{H}_{2} \mathrm{O}\right)_{n} \mathrm{H}^{+}$or other radical species are generated. ${ }^{30}$ However, our results revealed that the one-on-one exchange of sodium ion to proton proceeded because the sodium ions were swept away

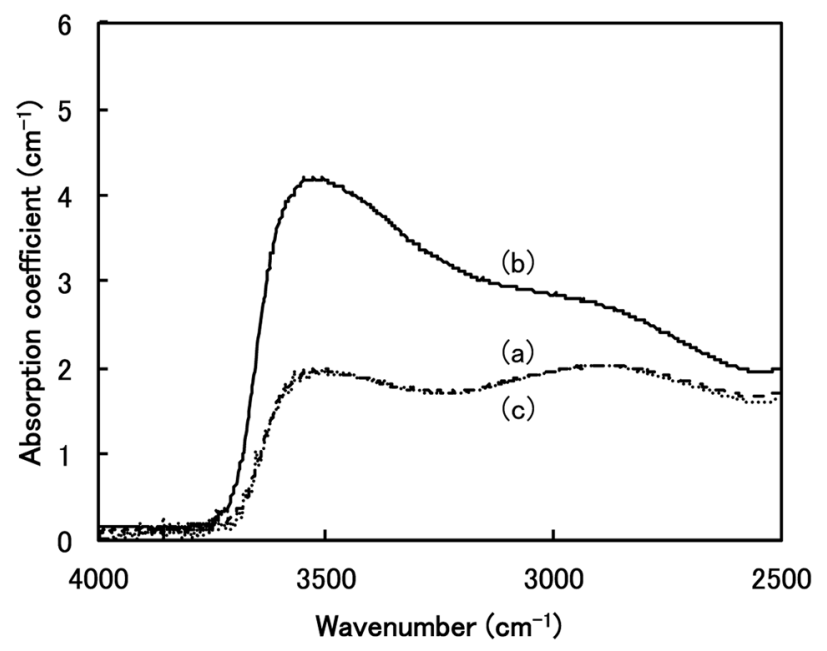

FIG. 8. IR absorption spectra (a) before and (b) after corona discharge treatment at $5.7 \mathrm{kV}, 100^{\circ} \mathrm{C}$ for $720 \mathrm{~min}$. Spectrum (c) was obtained after eliminating the anode side surface of $10 \mu \mathrm{m}$ by polishing.

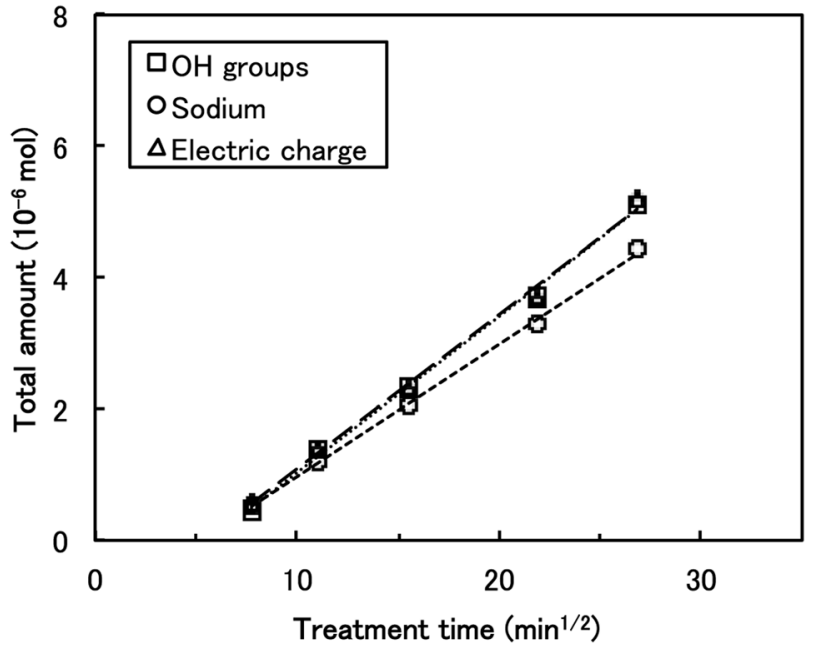

FIG. 9. Time dependence of (a) total electrical charge, (b) total precipitated sodium, and (c) $\mathrm{OH}$ concentration increased by the corona discharge treatment at $5.7 \mathrm{kV}, 100{ }^{\circ} \mathrm{C}$. These three amounts were estimated, respectively, from the measured current during the treatment, ICP-AES measurement and IR absorption spectra.

completely from the hydrogen injected layer and the total charge measured during the treatment agreed with the sodium ion concentration in the depletion layer. Therefore, the predominant ionization of gases can be written as $\mathrm{H}_{2}$ $\rightarrow 2 \mathrm{H}^{+}$: the reaction (2).

\section{B. Formation mechanism of sodium depletion layer}

Figure 10 presents the time dependence of the sodium depletion layer thickness by the corona discharge treatment obtained from the amount of the precipitated sodium (Figure 4). The sodium depletion layer thickness was fitted by the theoretical model developed by Prieto and Linares to analyze the ion exchange process assisted by a DC electric field for an optical waveguide fabrication. ${ }^{31}$ The time dependence of the sodium depletion layer thickness $l(t)$ is expressed as follows: ${ }^{31}$

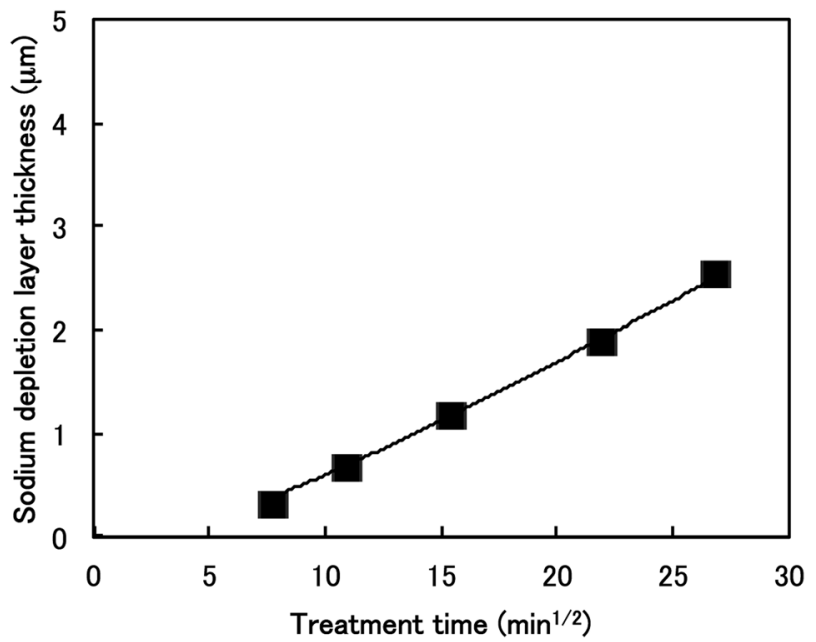

FIG. 10. Time dependence of the sodium depletion layer thickness by the corona discharge treatment at $5.7 \mathrm{kV}, 100^{\circ} \mathrm{C}$. The closed square symbol was obtained using the amount of precipitated sodium (Figure 4) and solid line was obtained using Eq. (5). 
TABLE I. Properties of a soda lime glass and experimental condition used for the calculation.

\begin{tabular}{lccc}
\hline \hline $\begin{array}{l}\text { Glass } \\
\text { thickness, }\end{array}$ & $\begin{array}{c}\text { Sodium } \\
\text { concentration }(\mathrm{mm})\end{array}$ & $\begin{array}{l}\mathrm{H}^{+} \text {mobility } \mu_{\mathrm{H}} \\
\left(\mathrm{C}^{2} \mathrm{~V}^{-1} \mathrm{~s}^{-1}\right)^{\mathrm{a}, 32}\end{array}$ & $\begin{array}{c}\mathrm{Na}^{+} \text {mobility } \mu_{\mathrm{Na}} \\
\left(\mathrm{m}^{2} \mathrm{~V}^{-1} \mathrm{~s}^{-1}\right)^{37}\end{array}$ \\
\hline 1 & $1.0 \times 10^{4}$ & $7 \times 10^{-19}$ & $7 \times 10^{-16}$ \\
\hline \hline
\end{tabular}

${ }^{\mathrm{a}}$ The $\mathrm{Na}^{+}$mobility is 1000 times as high as the $\mathrm{H}^{+}$mobility.

$$
l(t)=\left(\frac{1}{\alpha N_{H}}-1\right)\left[\sqrt{\frac{2 \alpha N_{H} \mu_{H} V}{\left(1-\alpha N_{H}\right)^{2}} t+L^{2}}-L\right] .
$$

In that equation, $L$ stands for the glass thickness, $V$ signifies the voltage across the glass, $\alpha=1+\mu_{H} / \mu_{N a}$ represents the ion-mismatched parameter, and $\mu_{H}$ and $\mu_{N a}$, respectively, denote the mobilities of protons and sodium ions. $N_{H}=C_{H} / C_{N a}^{0}$, which is the ratio of proton concentration $C_{H}$ to the intrinsic sodium ion concentration $C_{\mathrm{Na}}^{0}$, is assumed to be 1 because the sodium ions in the sodium depletion layer were exchanged completely to the protons. The values used for the calculation are presented in Table I. The calculated result agreed well with our experimentally obtained result. The sodium depletion layer thickness increased against the square root of time and the voltage across the glass $V$ was calculated to $0.2 \mathrm{kV}$ using Eq. (5). Considering that the total applied voltage was $5.7 \mathrm{kV}$ in the corona discharge treatment, then presumably, $5.5 \mathrm{kV}$ was consumed in the atmosphere to generate the protons that drifted onto the glass surface. As the results showed, we estimated the voltage $V_{\text {surf }}$ and the electric field $E_{\text {surf }}$ across the sodium depletion layer using the following equations, which can be derived from the equations in an earlier report: ${ }^{31}$

$$
\begin{gathered}
V_{\text {surf }}(t)=\frac{V}{\alpha}\left(1-\frac{L}{\sqrt{\frac{2 \alpha \mu_{H} V}{(1-\alpha)^{2}} t+L^{2}}}\right), \\
E_{\text {surf }}(t)=\frac{V}{(1-\alpha) \sqrt{\frac{2 \alpha \mu_{H} V}{(1-\alpha)^{2}} t+L^{2}}} .
\end{gathered}
$$

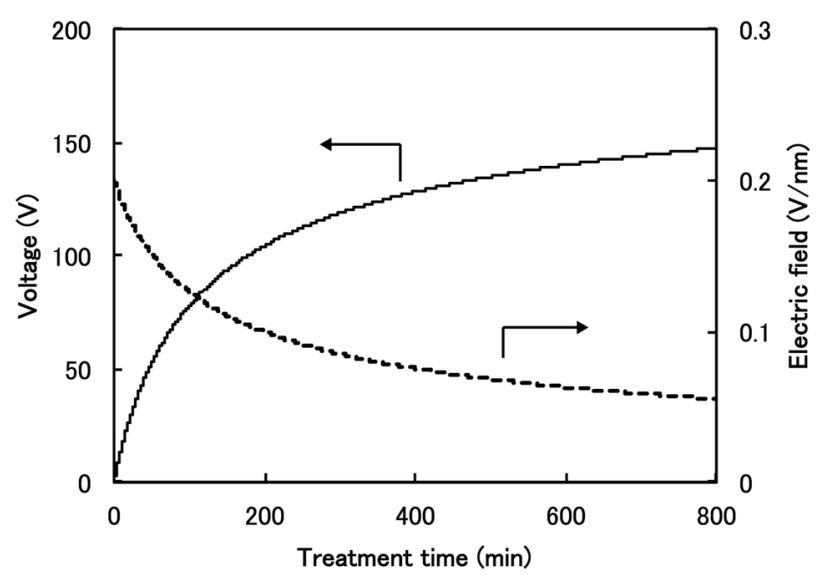

FIG. 11. Time dependence of voltage and electric field across the sodium depletion layer calculated, respectively, using Eqs. (6) and (7).
Figure 11 shows the calculated value for the voltage and the electric field across the sodium depletion layer during the corona discharge treatment using Eqs. (6) and (7). Results show that the large electric field was generated in the sodium depletion layer during the corona discharge treatment, which means that the electrical conductivity of the layer decreased significantly by the substitution of sodium ions with proton. Consequently, the voltage was concentrated in the thin layer. According to results of an earlier study, ${ }^{5}$ the conductivity of sodium depletion layer in a soda lime glass is comparable to that of a fused silica glass. Indeed, the mobility ratio $\left(\mu_{N a} / \mu_{H}\right)$ of sodium ion $\left(\mu_{N a}\right)$ and proton $\left(\mu_{H}\right)$ in a soda lime glass was reported as of the order of $10^{3} .{ }^{32-34}$ Results suggest that formation of the sodium depletion layer resulted from the large difference of the mobilities between sodium ion and proton.

Studies on the thermal poling to a soda lime glass reported the formation of the alkali depletion layer on the anode side surface under the condition of several kilovolts at around $200{ }^{\circ} \mathrm{C}$ in air. ${ }^{32,35}$ However, the substitution of sodium ion with proton by this method proceeds only slightly, which is a discriminate point from the corona discharge treatment. Krieger and Lanford investigated the transport phenomena of ions (sodium, calcium ions, and proton) in a soda lime glass with application of DC voltage using Rutherford backscattering technique. ${ }^{36}$ They used a "blocking electrode" to prevent the penetration of any ions, including proton to the glass from ambient air or the electrode. The results indicated that the sodium depletion layer thickness was about $300 \mathrm{~nm}$ after the treatment at $300 \mathrm{~V}$ and $150{ }^{\circ} \mathrm{C}$ over $60 \mathrm{~h}$. In contrast, our results indicate thickness of $3 \mu \mathrm{m}$ at $100{ }^{\circ} \mathrm{C}$ and $200 \mathrm{~V}$ (estimated voltage across the glass using Eq. (5)) for $12 \mathrm{~h}$ was reached. According to the previous study about thermal poling of the soda lime glass, ${ }^{32}$ the growth rate of the sodium depletion layer depends on the mobility of mobile ions, which are proton or oxygen ions, to compensate the sodium ion. The proton mobility is much greater than oxygen ion mobility. Therefore, the sodium depletion layer growth rate was increased by penetration of the proton from ambient atmosphere. During the corona discharge treatment, protons were introduced from the ambient atmosphere. Consequently the concentration of protons as $\mathrm{OH}$ groups in the sodium depletion layer reached the level of approximately $13 \mathrm{~mol}$. \%, which was comparable to the concentration of intrinsic sodium. Therefore, corona discharge treatment is expected to be useful for the non-contact substitution processing of alkali ion with protons for glasses and ceramics of several kinds.

\section{CONCLUSION}

Corona discharge was applied to soda lime glass at $100{ }^{\circ} \mathrm{C}$ in an atmosphere of 5 vol. $\% \mathrm{H}_{2}$ and 95 vol. $\% \mathrm{~N}_{2}$. The substitution of sodium ions with protons proceeded at the anode side surface during the treatment. The sodium depletion layer thickness increased as a function of the square root of time. The theoretical model predicts that a large electric field should be applied on the anode side glass surface during the treatment. The layer thickness was 
restricted by the mobility ratio of sodium ion and proton, which is in the order of $10^{3}$ in the soda lime glasses. The non-contact corona discharge treatment is expected to be useful for the formation of alkali-free and high-proton concentration surface on glasses and ceramics under a low temperature with atmospheric pressure.

\section{ACKNOWLEDGMENTS}

This work was supported by Asahi Glass Co. Ltd.

${ }^{1}$ G. W. Arnold, J. Non-Cryst. Solids 179, 288 (1994).

${ }^{2}$ T. Poszner, G. Schreiter, and R. Muller, J. Appl. Phys. 70, 1966 (1991).

${ }^{3}$ S. Deriano, T. Rouxel, S. Malherbe, J. Rocherulle, G. Duisit, and G. Jezequel, J. Eur. Ceram. Soc. 24, 2803 (2004).

${ }^{4}$ X. M. Liu and M. D. Zhang, Jpn. J. Appl. Phys., Part 1 40, 4069 (2001).

${ }^{5}$ Y. Enami, P. Poyhonen, D. L. Mathine, A. Bashar, P. Madasamy, S. Honkanen, B. Kippelen, N. Peyghambarian, S. R. Marder, A. K. Y. Jen, and J. Wu, Appl. Phys. Lett. 76, 1086 (2000)

${ }^{6}$ M. I. Petrov, A. V. Omelchenko, and A. A. Lipovskii, J. Appl. Phys. 109, 094108 (2011).

${ }^{7}$ Y. T. Ren, C. J. Marckmann, J. Arentoft, and M. T. Kristensen, IEEE Photon. Technol. Lett. 14, 639 (2002).

${ }^{8}$ N. J. Smith, M. T. Lanagan, and C. G. Pantano, J. Appl. Phys. 111, 083519 (2012).

${ }^{9}$ A. Narazaki, K. Tanaka, K. Hirao, and N. Soga, J. Am. Ceram. Soc. 81, 2735 (1998).

${ }^{10}$ A. L. Moura, M. T. de Araujo, E. A. Gouveia, M. V. D. Vermelho, and J. S. Aitchison, Opt. Express 15, 143 (2007).

${ }^{11}$ M. Leitner, H. Peterlik, B. Sepiol, H. Graener, M. Beleites, and G. Seifert, Phys. Rev. B 79, 153408 (2009).

${ }^{12}$ A. Abdolvand, A. Podlipensky, S. Matthias, F. Syrowatka, U. Gosele, G. Seifert, and H. Graener, Adv. Mater. 17, 2983 (2005).

${ }^{13}$ P. N. Brunkov, V. G. Melekhin, V. V. Goncharov, A. A. Lipovskii, and M. I. Petrov, Tech. Phys. Lett. 34, 1030 (2008)

${ }^{14}$ A. A. Lipovskii, V. G. Melehin, M. I. Petrov, Y. P. Svirko, and V. V. Zhurikhina, J. Appl. Phys. 109, 011101 (2011).
${ }^{15}$ H. J. Jung, Y. J. Park, S. H. Choi, J. M. Hong, J. Huh, J. H. Cho, J. H. Kim, and C. Park, Langmuir 23, 2184 (2007).

${ }^{16}$ K. Munakata, K. Harada, H. Anji, M. Itoh, T. Yatagai, and S. Umegaki, Opt. Lett. 26, 4 (2001).

${ }^{17}$ P. Cheben, F. del Monte, D. J. Worsfold, D. J. Carlsson, C. P. Grover, and J. D. Mackenzie, Nature 408, 64 (2000).

${ }^{18}$ M. Stahelin, C. A. Walsh, D. M. Burland, R. D. Miller, R. J. Twieg, and W. Volksen, J. Appl. Phys. 73, 8471 (1993).

${ }^{19}$ F. Chaput, D. Riehl, J. P. Boilot, K. Cargnelli, M. Canva, Y. Levy, and A. Brun, Chem. Mater. 8, 312 (1996).

${ }^{20} \mathrm{~J}$. A. Giacometti and O. N. Oliveira, IEEE Trans. Electr. Insul. 27, 924 (1992).

${ }^{21}$ J. A. Giacometti, P. A. Ribeiro, M. Raposo, J. N. Maratmendes, J. S. C. Campos, and A. S. Dereggi, J. Appl. Phys. 78, 5597 (1995).

${ }^{22}$ D. Sakai, K. Harada, S. Kamemaru, and T. Fukuda, Appl. Phys. Lett. 90, 061102 (2007).

${ }^{23}$ D. Sakai, K. Harada, S. Kamemaru, D. Barada, F. Sato, and T. Fukuda, Jpn. J. Appl. Phys. Part 1 47, 7929 (2008).

${ }^{24}$ D. Sakai, D. Miho, K. Harada, D. Barada, and T. Fukuda, Jpn. J. Appl. Phys. Part 1 49, 01 AE01 (2010).

${ }^{25}$ D. Sakai, K. Harada, S. Kamemaru, D. Barada, F. Sato, and T. Fukuda, Opt. Rev. 16, 335 (2009).

${ }^{26}$ D. Sakai, K. Harada, S. Kamemaru, and T. Fukuda, Opt. Rev. 14, 339 (2007).

${ }^{27}$ H. Behrens and A. Stuke, Glass Sci. Technol. 76, 176 (2003).

${ }^{28}$ U. Harder and H. Geissler, Fresenius' J. Anal. Chem. 361, 585 (1998).

${ }^{29}$ D. J. Mellor and J. R. Travis, J. Phys. D: Appl. Phys. 5, 1117 (1972).

${ }^{30}$ M. M. Shahin, J. Chem. Phys. 45, 2600 (1966).

${ }^{31}$ X. Prieto and J. Linares, Opt. Lett. 21, 1363 (1996).

${ }^{32}$ M. Dussauze, V. Rodriguez, A. Lipovskii, M. Petrov, C. Smith, K. Richardson, T. Cardinal, E. Fargin, and E. I. Kamitsos, J. Phys. Chem. C 114, 12754 (2010).

${ }^{33}$ G. Hetherington, K. H. Jack, and M. W. Ramsay, Phys. Chem. Glasses 6, 6 (1965).

${ }^{34}$ W. A. Lanford, K. Davis, P. Lamarche, T. Laursen, R. Groleau, and R. H. Doremus, J. Non-Cryst. Solids 33, 249 (1979).

${ }^{35}$ E. C. Ziemath, V. D. Araujo, and C. A. Escanhoela, J. Appl. Phys. 104, 054912 (2008).

${ }^{36}$ U. K. Krieger and W. A. Lanford, J. Non-Cryst. Solids 102, 50 (1988).

${ }^{37}$ C. M. Lepienski, J. A. Giacometti, G. F. L. Ferreira, F. L. Freire, and C. A. Achete, J. Non-Cryst. Solids 159, 204 (1993). 